\title{
The effectiveness of anaerobic digestion in removing estrogens and nonylphenolethoxylates
}

\author{
N. Paterakis ${ }^{a}$, T.Y. Chiu ${ }^{a}$, Y.K.K. Koh ${ }^{b}$, J.N. Lester ${ }^{a}$, E.J. McAdamª ${ }^{a}$ M.D. Scrimshaw ${ }^{c}$, A. \\ Soares ${ }^{\mathrm{a}}$, E. Cartmell ${ }^{\mathrm{a} *}$
}

a Cranfield Water Science Institute, Cranfield University, Bedfordshire MK43 0AL, UK

b Public Utilities Board, Technology and Water Quality Office, 40 Scotts Road No. 15-01, Environmental Building, 228231, Singapore

c Institute for the Environment, Brunel University, Uxbridge, Middlesex UB8 3PH, UK

Keywords: Anaerobic digestion; Sludge; Mesophilic; Thermophilic; 17a-Ethinylestradiol

\section{Abstract}

The fate and behaviour of two groups of endocrine disrupting chemicals, steroid estrogens and nonylphenol ethoxylates, have been evaluated during the anaerobic digestion of primary and mixed sewage sludge under mesophilic and thermophilic conditions. Digestion occurred over six retention times, in laboratory scale reactors, treating sludges collected from a sewage treatment works in the United Kingdom. It has been established that sludge concentrations of both groups of compounds demonstrated temporal variations and that concentrations in mixed sludge were influenced by the presence of waste activated sludge as a result of transformations during aerobic treatment. The biodegradation of total steroid estrogens was $>50 \%$ during primary sludge digestion with lower removals observed for mixed sludge, which reflected bulk organic solids removal efficiencies. The removal of nonylphenol ethoxylates was greater in mixed sludge digestion (>58\%) compared with primary sludge digestion and did not reflect bulk organic removal efficiencies. It is apparent that anaerobic digestion reduces the concentrations of these compounds, and would therefore be expected to confer a degree of protection against exposure and transfer of both groups of compounds to the receiving/re-use environment.

*Corresponding author. Tel.: +44 1234 758366; fax: +44 1234751671.

E-mail address: e.cartmell@cranfield.ac.uk (E. Cartmell). 


\section{Introduction}

Numerous organic micropollutants are present in crude sewage and these have been the cause of concern for many years [1]. Recently those organic micropollutants with endocrine disrupting ability have been the subject of major research investigations [2-5]. Endocrine disruption in fish has been predominantly attributed to the presences of free natural estrogens such as estrone (E1) and 17ß-estradiol (E2) together with the synthetic estrogen 17a-ethinylestradiol (EE2) as well as nonylphenols (NP) and nonylphenol ethoxylates (NPEOs). Whilst conventional wastewater treatment plants are able to breakdown endocrine disrupting chemicals (EDCs) [6] as presently operated this capability is limited $[3,5]$. Once in the receiving waters, these compounds are likely to undergo biotransformation and EDCs have the potential to bio-concentrate $[7,8]$ and accumulate in organisms. Such complex behaviour leads to uncertainty in determining the significance $f$ their occurrence in the environment [10].

Those compounds which have not biodegraded or have only partially biodegraded during wastewater treatment may be adsorbed to the sewage solids [2,3] and will be subject to further treatment prior to reuse. A common form of sewage sludge treatment is anaerobic digestion (AD). Studies of the fate and behaviour of EDCs during anaerobic digestion are limited [11]. Undoubtedly the analytical difficulties of determining these compounds in such complex matrices at environmental concentrations (ng g-1) have been a major constraint on such research [12,13]. However, some studies have been undertaken. One of these was by Carballa et al. [14] who examined pharmaceutical and personal care products. The behaviour of E1, E2 and EE2 in laboratory scale anaerobic sludge digesters under mesophilic conditions $\left(3^{\circ} \mathrm{C}\right)$ with a sludge retention time (SRT) of $30 \mathrm{~d}$ and under thermophilic conditions $\left(5^{\circ} \mathrm{O}\right)$ ) with an SRT of $20 \mathrm{~d}$ was examined. Removal of EE2 was reported to be initially $60 \%$ rising to $90 \%$ with time. These workers also reported the reduction of $\mathrm{E} 1$ to $\mathrm{E} 2$ and the subsequent removal of $\mathrm{E} 2$.

In anaerobic batch studies of four different sludge types [15] the transformation of E1 to E2 was observed, but no overall reduction in the combined concentrations of E1 and E2 was detected indicative of no further breakdown of E2. This observation was true for all four sludge types examined: digested pig manure; granular up-flow anaerobic sludge blanket (UASB) sludge from a paper mill; flocculent sludge from a pilot-scale UASB septic tank; and activated sludge from a full-scale oxidation ditch. The removal of EE2 was not observed for any sludge type. It was recognized by de Mes et al. [15] that information on the role of conjugation in determining the fate of estrogens in all forms of wastewater treatment 
including anaerobic sludge digestion was lacking. However, it is known that sulphate conjugates are more stable than gluconarides [16]. Reports of the degradation of alkylphenol ethoxylates (APEOs) in anaerobic conditions are more scarce in comparison to steroid estrogens. In anaerobic, as well as aerobic conditions, the ethoxylate chain of higher ethoxylate NPEOs is shortened until persistent short-chained NP1-2EOs and NP are formed. This breakdown proceeds by the stepwise removal mechanism of one ethylene glycol unit $[2,17]$. It appears that NP, a major product of degradation, is frequently reported as not undergoing further transformation $[18,19]$. However, NP degradation under anaerobic conditions has been recently demonstrated [19-21].

The objective of this study was to determine the fate and behaviour of estrogens and NPEOs, already present in primary and mixed sludge (primary plus waste activated sludge, WAS) under both mesophilic and thermophilic conditions at environmental concentrations. This means that the complex interactions between indigenous compounds and sludge types will reflect reality when evaluating the impact of different sludge treatment approaches on degradation. Eggen and Majcherczyk [22] previously demonstrated that spiking experiments, as frequently undertaken, do not represent reality because added compounds behave differently to "aged" compounds, which are strongly linked to the matrix and therefore require more energy to be biodegraded [23].

\section{Material and methods}

\subsection{Sludge types and collection}

The sludges were collected under dry weather conditions on two occasions (April 2007 and April 2008) from a UK sewage treatment works (STWs) for the mesophilic and thermophilic trials respectively. Therefore, variations in sewage sludge composition within each trial were eliminated as an experimental variable. It was necessary to collect sludge on two occasions due to storage capacity limitations which resulted in solid and nonylphenoxy acetic acid(NP1-3EC) loading variations between the trials. The STWs was an activated sludge plant with a population equivalent (PE) of 155,000and a trade input of c. $10 \%$. Sludge stabilization at the STWs was carried out by two continuous mesophilic ( $35{ }^{\circ} \mathrm{C}$ ) anaerobic digesters (450 m3d-1) with $28 \mathrm{~d}$ nominal solid retention time (SRT). The digesters were fed every hour for 20 min continuously with mixed sludge (primary and waste activated sludge at a ratio of $60 \%(\mathrm{v} / \mathrm{v})$ primary and $40 \%(\mathrm{v} / \mathrm{v})$ WAS) from a balancing tank. The sludge types used in this study were primary sludge and thickened mixed sludge. 
Primary sludge was collected directly from the pumped outlet of the primary sedimentation tank. Mixed sludge (primary and WAS) was sampled directly from a balancing tank. The inoculum sludge (10 I digested sludge) was collected directly from the mesophilic anaerobic digesters. Sludge processing commenced within $6 \mathrm{~h}$ of sampling. Sludges were sieved through a $2 \mathrm{~mm}$ mesh (Alana Ecology Ltd., Bishop's Castle, UK) and transferred to $1 \mathrm{I}$ acid washed polypropylene containers (Fisher Scientific, Loughborough, UK) for storage at $25^{\circ} \mathrm{C}$ until needed.

\subsection{Laboratory scale anaerobic digesters}

Laboratory scale anaerobic digesters (1.5 I working volume) were operated in duplicate at each digestion temperature [11]. Each digester comprised a borosilicate glass bowl and lid containing five access ports. The digesters were kept in a water bath at $35^{\circ} \mathrm{C}$ (mesophilic) or $55^{\circ} \mathrm{C}$ (thermophilic) and stirred automatically for $10 \mathrm{~min}$ in every hour at approximately 100 rpm. For the mesophilic trial the digesters were initially filled with the digested seed sludge from the selected STW. The seed sludge for the thermophilic digesters was obtained by operating an additional 5 I laboratory digester at mesophilic temperature and increasing the temperature by $0.3^{\circ} \mathrm{C} d-1$ until the digester was operating successfully at $55^{\circ} \mathrm{C}$. Then two batches of $1.5 \mathrm{I}$ thermophilic seed sludge were removed to start the thermophilic trial digesters. This was required as no thermophilic sludge digesters were operating in the UK from which an inoculum could be sourced. The digesters were stabilized for two retention times and were then operated for a further six solid retention times which was $180 \mathrm{~d}$ for the mesophilic trial and $90 \mathrm{~d}$ for the thermophilic trial.

To feed the digesters, frozen feed sludge was thawed overnight and warmed to $35^{\circ} \mathrm{C}$ or $55^{\circ} \mathrm{C}$. The hydraulic retention time (HRT) was $30 \mathrm{~d}$ at $35^{\circ} \mathrm{C}$ (mesophilic) or $15 \mathrm{~d}$ at 55을 (thermophilic). Gas was collected by the displacement of acidified water [11] and measured at atmospheric pressure by the use of a balancing reservoir. The methane $(\mathrm{CH} 4)$ content was analysed using a Servomex 1440D infra-red analyser (Servomex Group Ltd., Crowborough, UK) modified for $\mathrm{CH} 4$ analysis. Redox potential and $\mathrm{pH}$ were monitored using portable meters (Ion Meter 3340, Jenway Ltd., Essex, UK and VWR pH meter-100 (VWR International Limited, Lutterworth UK). Temperature was measured using a mercury and glass thermometer. On a weekly basis total solids (TS), volatile solids (VS) and alkalinity were determined using standard methods [11]. Volatile fatty acids (VFAs) (acetic acid, butyric acid, propionic acid and valeric acid) were separated and quantified using HPLC (VP Series, Shimadzu, Milton Keynes, UK) fitted with an Aminex® fermentation column 
(150mm $\times 7.8 \mathrm{~mm}, 5 \mu \mathrm{m}$; Bio-Rad Laboratories, Hemel Hempstead, UK) with detection at $208 \mathrm{~nm}$.

\subsection{Analytical procedure for the determination of estrogens and nonylphenol ethoxylates}

The standards, reagents and analytical method used in the determination of estrogens (estrone (E1), 17ß-estradiol (E2), estriol (E3), sulfate conjugate of estrone (E1-3S) and 17aethinylestradiol(EE2) and alkylphenolic compounds (nonylphenols (NP), nonylphenol polyethoxylates (NPEO), and nonylphenol ethoxycarboxylates(NPEC)) have been reported previously $[24,25]$.

In summary, steroid estrogens and nonylphenolic compounds were solvent extracted separately from freeze-dried sludge. Therefore, the results reported here are for total concentrations in the sludge (solid and liquid phases). A Multi-Reax system (Heidolph Instruments, Schwabach, Germany) was applied for solvent extraction using $10 \mathrm{ml}$ ethyl acetate for steroid estrogens and10 ml MeOH/acetone (1:1) for the alkylphenolics in $25 \mathrm{ml}$ Teflon tubes with mechanical shaking for $1 \mathrm{~h}$ followed by centrifugation at $1500 \times \mathrm{g}$ for 10 min. The extraction was repeated twice and combined supernatants were evaporated to approximately $0.2 \mathrm{ml}$ then made to $2 \mathrm{ml}$ with hexane. The separate steroid estrogen and alkylphenolic solutions were subjected to clean-up bypassing through a $500 \mathrm{mg} / 3 \mathrm{ml}$ silica solid phase extraction (SPE) cartridge (Waters Ltd., Watford, UK). The alkylphenolic eluates were then quantified whilst the combined eluates for steroid estrogens were evaporated to dryness on a rotary evaporator then re-constituted in $2 \mathrm{ml}$ of $\mathrm{DCM} / \mathrm{MeOH}$ (90:10). This purified sample was then subjected to further clean-up by gel permeation chromatography (GPC), anion-exchange SPE and finally quantification by liquid chromatography tandem mass spectrometry in ESI mode(LC/ESI/MS/MS) using an HPLC (Waters Alliance HPLC system 2695) coupled to a Waters Quattro Premier XE mass spectrometer with a Z-Spray ESI source (Micromass, Manchester, UK) as described previously [24]. Further method detail is available in Chiu et al. [26] and Koh et al. [27]. The limit of detection in sewage sludge matrices for NP, NPEOs and NPECs ranged from 6 to $60 \mu \mathrm{gg}^{-1}$ [27] whilst the limit of detection for estrogens (E1, E1-3S, E2, E3 and EE2) were2.1-5.3 $\mathrm{ng} \mathrm{g}^{-1}$ [26]. 


\section{Results and discussion}

The overall performance of the reactors in terms of gas volume, percentage methane, VFAs and solids reduction are presented in Table 1. Mean pH values, VFA contents and alkalinity lie within the typical range observed for anaerobic digestion [28] which is indicative of a well established methanogenic population. Redox potential (ORP) values, in all types of digesters, were always slower than $-320 \mathrm{mV}$ which favoured the survival of anaerobes and the enzymatic activity of methane-forming bacteria during the entire digestion periods. The solids loading rates for the digesters were $0.8-1.6 \mathrm{~kg} \mathrm{VS} \mathrm{m}^{-3} \mathrm{~d}^{-1}$ and $1.9-3.0 \mathrm{~kg} \mathrm{VS} \mathrm{m}^{-3} \mathrm{~d}^{-1}$ for mesophilic and thermophilic digesters. These values are in the range of those reported for digested sludge [28]. The gas production rate of the thermophilic process $\left(0.7-1.2 \mathrm{~m}^{3} \mathrm{~m}-3^{\mathrm{d}-}\right.$ $\left.{ }^{1}\right)$ was higher than the mesophilic process $\left(0.5 \mathrm{~m}^{3} \mathrm{~m}-3 \mathrm{~d}^{-1}\right.$. However, the average methane content of the biogas was similar in both digesters(73-75\%).

\subsection{Effect of sludge type on steroid estrogen removal}

Storage capacity necessitated collection of sludge on two occasions, once for the mesophilic experiments in April 2007 and once for the thermophilic experiments in April 2008. Thus influent sludge concentrations reflected not only differences in sludge type (primary or mixed), but also temporal variation (Table 1). The concentration of E1 varied by a factor of 2.5 for the primary sludge and 2.8 for the mixed sludge between the sampling periods. However, although the concentration of $\mathrm{E} 1$ varied between the sampling periods, the proportion of $\mathrm{E} 1$ remained consistent at69-78\% of the total estrogens. Primary sludge concentrations for E1were 158 and $64.3 \mu \mathrm{g} \mathrm{kg}^{-1} \mathrm{dw}$ for the April 2007 and 2008 periods respectively which were higher than those estimated by Andersen et al. [6] of c. $30 \mu \mathrm{g}$ $\mathrm{kg}^{-1} \mathrm{dw}$ (for E1 + E2). Variations for the estrogens E2, E3 and the conjugate E1-3S for both sludge types were not as marked between the sample periods with the influent concentrations varying by $3-3.6 \mu \mathrm{g} \mathrm{kg}^{-1} \mathrm{dw}$. However, the synthetic estrogen(EE2) exhibited a variation factor of two, between 9 and $18 \mathrm{\mu g} \mathrm{kg}^{-1} \mathrm{dw}$ for the primary sludge. The mixed sludge EE2 concentrations were equivalent at $10 \mathrm{\mu g} \mathrm{kg}^{-1} \mathrm{dw}$ which was equivalent to Muller et al. [29]. It is postulated that variation in sewage treatment works operating conditions, for example flow to works or presence of return liquors, may have contributed to the temporal variations observed in this study. 
Table 1 Influent sludge characteristics, operational conditions and digester performance at mesophilic and thermophilic temperatures after six retention times.

\begin{tabular}{|c|c|c|c|c|}
\hline \multirow[b]{2}{*}{ Influent sludges } & \multicolumn{2}{|c|}{$\begin{array}{c}\text { Mesophilic } \\
2007 \text { sampling }\end{array}$} & \multicolumn{2}{|c|}{$\begin{array}{l}\text { Thermophilic } \\
2008 \text { sampling }\end{array}$} \\
\hline & $\begin{array}{l}\text { Primary } \\
\text { sludge }\end{array}$ & Mixed sludge & Primary sludge & Mixed sludge \\
\hline $\mathrm{TS}\left(\mathrm{g} \mathrm{I}^{-1}\right)$ & $51.1 \pm 3.7$ & $57.1 \pm 4.3$ & $39.5 \pm 0.1$ & $49.7 \pm 0.1$ \\
\hline $\operatorname{VS}\left(\mathrm{g} \mathrm{l}^{-1}\right)$ & $36.5 \pm 2.6$ & $44.0 \pm 3.0$ & $29.2 \pm 0.1$ & $38.1 \pm 0.1$ \\
\hline VFA (mg acetic acid ${ }^{-1}$ ) & $1314 \pm 68$ & $1592 \pm 44$ & $1168 \pm 98$ & $1470 \pm 52$ \\
\hline Estrone (E1) $\mu \mathrm{g} \mathrm{kg}^{-1} \mathrm{dw}$ & 158 & 90 & 64.3 & 32.3 \\
\hline $17 \beta$-estradiol (E2) & 9 & 6 & 6 & 3 \\
\hline Estriol (E3) & 9 & 8 & 6 & \\
\hline Estrone-3-sulfate (E1-3S) & 7.6 & 7 & 4 & 4 \\
\hline 17 $\alpha$-ethinyl estradiol (EE2) & 18 & 10 & 9 & 10 \\
\hline 4-nonylphenol (NP) $\mathrm{mg} \mathrm{kg}^{-1} \mathrm{dw}$ & 0.3 & 0.23 & 0.23 & 0.1 \\
\hline $\begin{array}{l}\text { Nonylphenoxy acetic acids }\left(\mathrm{NP}_{1-}\right. \\
\left.{ }_{3} \mathrm{EC}\right) \mathrm{mg} \mathrm{kg}^{-1} \mathrm{dw}\end{array}$ & 26.5 & 241.5 & 0.1 & 0.08 \\
\hline $\begin{array}{l}\text { Nonylphenol monoethoxylate and } \\
\text { diethoxylate }\left(\mathrm{NP}_{1-2} \mathrm{EO}\right) \mathrm{mg} \mathrm{kg}^{-1} \mathrm{dw}\end{array}$ & 2.1 & 1.7 & 15 & 90 \\
\hline $\begin{array}{l}\text { Nonylphenol polyethoxylates }\left(\mathrm{NP}_{3-}\right. \\
\left.{ }_{12} \mathrm{EO}\right) \mathrm{mg} \mathrm{kg}^{-1} \mathrm{dw}\end{array}$ & 1.5 & 0.7 & 1.3 & 0.7 \\
\hline \multicolumn{5}{|l|}{ Operational conditions } \\
\hline $\mathrm{T}\left({ }^{\circ} \mathrm{C}\right)$ & $35 \pm 0.2$ & $35 \pm 0.2$ & $55 \pm 0.2$ & $55 \pm 0.2$ \\
\hline $\mathrm{SRT}(\mathrm{d})$ & 30 & 30 & 15 & 15 \\
\hline OLR $\left(k g\right.$ VS m $\left.\mathrm{m}^{-3} \mathrm{~d}^{-1}\right)$ & $1.3 \pm 0.1$ & $1.5 \pm 0.1$ & $1.9 \pm 0.0$ & $2.5 \pm 0.0$ \\
\hline $\mathrm{TS}\left(\mathrm{g} \mathrm{l}^{-1}\right)$ & $26.7 \pm 2.3$ & $38.5 \pm 1.3$ & $22.7 \pm 1.8$ & $33.9 \pm 1.3$ \\
\hline $\operatorname{VS}\left(\mathrm{gl}^{-1}\right)$ & $19.5 \pm 1.6$ & $23.9 \pm 2.0$ & $11.5 \pm 4.5$ & $22.0 \pm 2.2$ \\
\hline $\mathrm{pH}$ & $7.1 \pm 0.1$ & $7.5 \pm 0.1$ & $7.2 \pm 0.0$ & $7.6 \pm 0.1$ \\
\hline $\mathrm{ORP}(\mathrm{mV})$ & $-320.8 \pm 12.8$ & $-380.6 \pm 29.8$ & $-411.6 \pm 36.9$ & $-419.0 \pm 34.9$ \\
\hline VFA (mg acetic acid $I^{-1}$ ) & $176.4 \pm 7.3$ & $132.9 \pm 17.3$ & $1098.5 \pm 189.6$ & $829.3 \pm 145.9$ \\
\hline Total alkalinity (mg l'-1) & $2399 \pm 37$ & $5362 \pm 63$ & $4000 \pm 453$ & $4770 \pm 85$ \\
\hline \multicolumn{5}{|l|}{ Biogas } \\
\hline Daily production $\left(\mathrm{Id}^{-1}\right)$ & $0.8 \pm 0.0$ & $0.8 \pm 0.1$ & $1.0 \pm 0.1$ & $1.6 \pm 0.1$ \\
\hline $\operatorname{GRP}\left(m^{3} \mathrm{~m}^{-3} \mathrm{~d}^{-1}\right)$ & $0.51 \pm 0.0$ & $0.52 \pm 0.0$ & $0.67 \pm 0.0$ & $1.08 \pm 0.0$ \\
\hline $\operatorname{SGP}\left(\mathrm{m}^{3} \mathrm{CH}_{4} \mathrm{~kg}^{-1} \mathrm{VS}_{\text {removed }}\right)$ & $0.7 \pm 0.1$ & $0.6 \pm 0.1$ & $0.4 \pm 0.1$ & $0.7 \pm 0.1$ \\
\hline Biogas yield $\left(\mathrm{m}^{3} \mathrm{~kg}^{-1} \mathrm{VS}_{\text {removed }}\right)$ & $0.95 \pm 0.2$ & $0.80 \pm 0.1$ & $0.60 \pm 0.1$ & $1.02 \pm 0.1$ \\
\hline \multicolumn{5}{|l|}{ Removal efficiencies (\%) } \\
\hline VS & $53.5 \pm 6.9$ & $40.1 \pm 2.1$ & $43.2 \pm 3.0$ & $32.4 \pm 1.0$ \\
\hline TS & $47.3 \pm 8.5$ & $33.7 \pm 4.6$ & $37.0 \pm 4.4$ & $29.8 \pm 2.6$ \\
\hline $\mathrm{g} \mathrm{VS}_{\text {removed }} \mathrm{d}^{-1}$ & $1.07 \pm 0.1$ & $0.98 \pm 0.1$ & $2.24 \pm 0.2$ & $1.84 \pm 0.1$ \\
\hline
\end{tabular}

Key: TS=Total Solids; VS=Volatile Solids; VFA=Volatile Fatty Acids; T= temperature; SRT=Solid Retention Time; $\mathrm{OLR}=$ Organic Loading Rate; ORP=Oxidation/Reduction Potential; GRP=Gas Production Rate; $\mathrm{SGP}=$ Specific Gas Production 
Sludge type had an impact on the initial concentrations of steroid estrogens. In the primary sludge feed the concentration order was E1 > EE2 > E2 E3 > E1-3S whilst in the mixed sludge feed the concentrations were in the order of E1 >EE2 > E3 >E13S E2. This was indicative of biodegradation/biotransformation in the activated sludge plant, which produced the WAS component of the mixed sludge as there was a higher proportion of E3 which was a degradation product of $\mathrm{E} 1$ in the activated sludge process.

During digestion, E1 was reduced to E2 in all sludge types, which is consistent with the observations of Carballa et al. [14,30], de Meset al. [15] and Hospido et al. [31]. Oxidation of E2 to E1 has also been reported in anaerobic sediments spiked with E2 (5 $\left.\mathrm{mg} \mathrm{l}^{-1}\right)$ [32]. It is apparent that the transformations of $\mathrm{E} 1$ and $\mathrm{E} 2$ are effected by their initial concentrations. If higher concentrations of E2 dominate then E2 oxidation occurs as observed by [32]. However, in this study higher starting concentrations of E1 were present which were reduced to E2. Overall there is evidence that equilibrium betweenE1 and E2 was achieved. Nevertheless, the different sludge types had an effect on the transformation rate of $\mathrm{E} 1$ and E2. An examination of Fig. 1 demonstrates that for primary sludge a $50 \%$ reduction of E1 to E2 occurred after two retention times ( $60 \mathrm{~d}$ ) in comparison to the first retention time (30 d) for the mixed sludge at the mesophilic temperatures with the rate of production of E2 faster in the first retention period for mixed sludge $\left(0.006 \mu \mathrm{g} \mathrm{d}^{-1}\right)$ as opposed to primary sludge $\left(0.001 \mu \mathrm{g} \mathrm{d}^{-1}\right)$. A comparable trend occurred the thermophilic temperature although this was less pronounced. The implication was that the mixed sludge biomass, which at start up had previously been acclimated to steroid estrogens during the activated sludge process, could adapt to anaerobic conditions and continue to function effectively [33]. The overall removal of steroid estrogens in the primary sludge was $53 \%$ and $51 \%$ for ¿EST (sum of endocrine steroid estrogens E1, E2, E3, E1-3S and EE2) at mesophilic and thermophilic temperatures respectively compared with lower overall removals for mixed sludge of $39 \%$ and $12 \%$ at mesophilic and thermophilic temperatures respectively (Fig. 2). The overall percentage removals therefore reflected the bulk organic transformations in the anaerobic digesters (Table 1), with the highest steroid estrogen removal occurring in mesophilic digestion of primary sludge and the lowest in the thermophilic digestion of mixed sludge. However, the presence of nitrate in mixed sludge (up to $28 \mathrm{NO}-\mathrm{N} \mathrm{mg} \mathrm{^{-1 }}$ ), which is not present in the primary sludges, could also influence steroid estrogen transformations with the final steady state concentration of E2 depending on the electron-accepting condition. Czajka and Londry [32] have demonstrated that nitrate, as an electron acceptor, played a role in the bio-transformations between E1 and E2. 

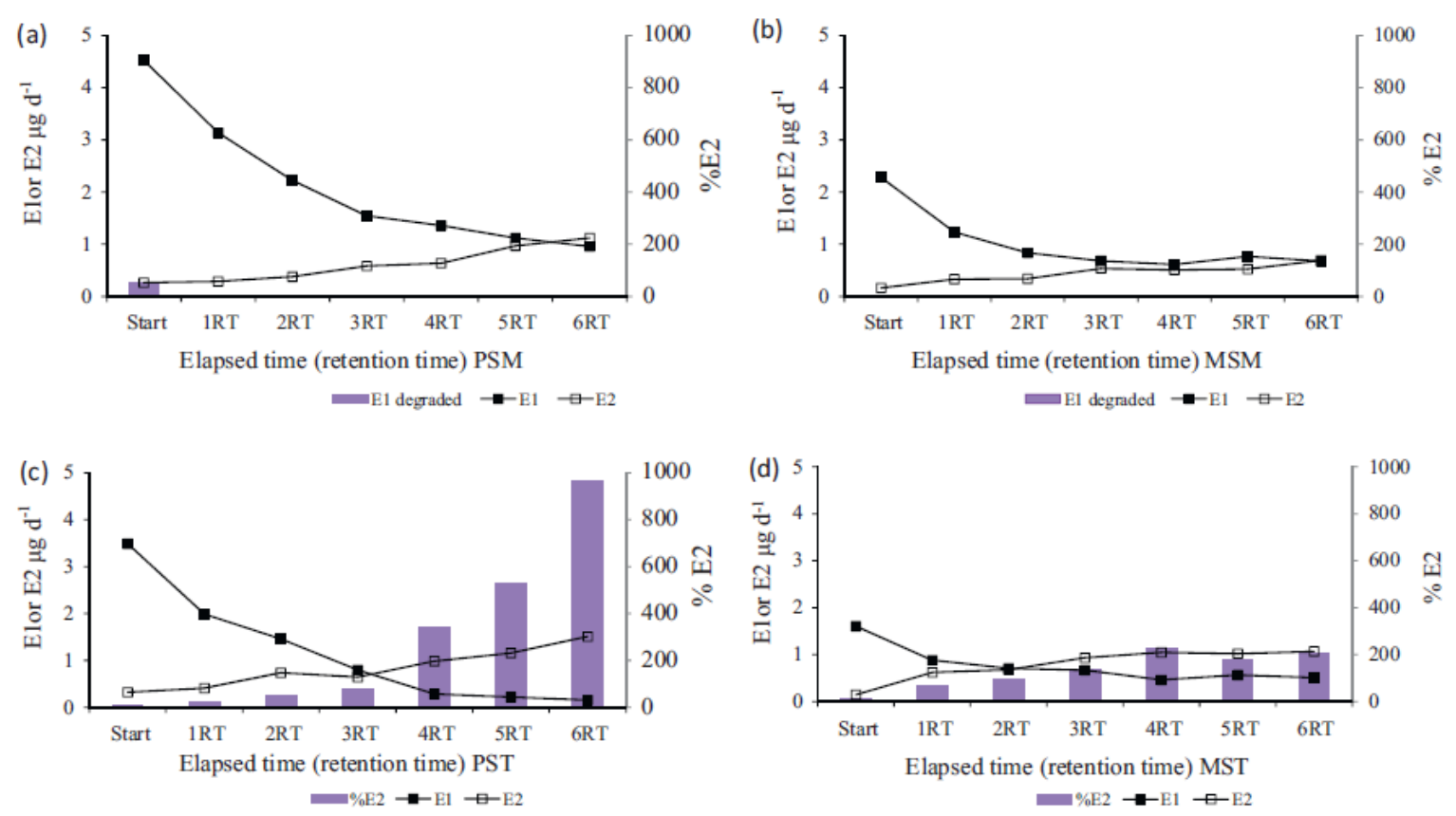

Fig. 1. The mass $\left(\mu \mathrm{g} \mathrm{d}^{-1)}\right.$ of $\mathrm{E} 2$ and $\mathrm{E} 1$ and the \%E2 of $\mathrm{E} 1$ at each retention period for (a) mesophilic digestion of primary sludge (PSM), (b) mesophilic digestion of mixed sludge (MSM), (c) thermophilic digestion of primary sludge and (d) thermophilic digestion of mixed sludge.

Table 2 Mass flux removal/accumulation percentages and first order rate constant for steroid estrogens and nonylphenol ethoxylates during digestion of primary and mixed sludge(at the 6th retention time) under mesophilic and thermophilic conditions.

Mesophilic

Thermophilic

\begin{tabular}{lllllllll}
\hline & \multicolumn{2}{c}{ Primary Sludge } & \multicolumn{2}{c}{ Mixed Sludge } & \multicolumn{3}{c}{ Primary Sludge } & \multicolumn{2}{c}{ Mixed Sludge } \\
\hline & $\%$ & $k\left(d^{-1}\right)$ & $\%$ & $k\left(d^{-1}\right)$ & $\%$ & $k\left(d^{-1}\right)$ & $\%$ & $k\left(d^{-1}\right)$ \\
\hline EE2 & $34 \%$ & 0.013 & $4 \%$ & 0.0052 & $43 \%$ & 0.052 & $14 \%$ & 0.075 \\
E2 & $-324 \%$ & -0.026 & $-325 \%$ & -0.026 & $-367 \%$ & -0.015 & $-621 \%$ & -0.051 \\
E1 & $79 \%$ & 0.117 & $70 \%$ & 0.081 & $96 \%$ & 0.042 & $68 \%$ & 0.046 \\
E3 & $45 \%$ & 0.025 & $43 \%$ & 0.023 & $17 \%$ & 0.021 & $4 \%$ & 0.020 \\
E1-3S & $36 \%$ & 0.017 & $21 \%$ & 0.011 & $30 \%$ & 0.021 & $28 \%$ & 0.024 \\
NP & $0 \%$ & 0.025 & $100 \%$ & 0.030 & $50 \%$ & 0.091 & $100 \%$ & 0.350 \\
NPEC & -215 & $n / c$ & 0.0035 & $n / c$ & $>-1000$ & $n / c$ & $-5800 \%$ & $n / c$ \\
NP $_{1-2}$ EO & $88 \%$ & $n / c$ & -0.0274 & $n / c$ & $2.5 \%$ & $n / c$ & $100 \%$ & $n / c$ \\
NP $_{3-12}$ EO & $66 \%$ & $n / c$ & $67 \%$ & $n / c$ & $73 \%$ & $n / c$ & $83 \%$ & $n / c$ \\
\hline
\end{tabular}

First order rate constant $k\left(d^{-1}\right)$ was calculated for the $6^{\text {th }}$ SRT according to mass flux $=\left(S_{0}-S_{e}\right) \times\left(\frac{v}{R}\right)$

Where, $S_{0}=$ volumetric cumulative influent substrate concentration $\left(\mu \mathrm{g} \mathrm{m}^{-3} \mathrm{~d}^{-1}\right)$, Se = volumetric cumulative effluent substrate concentration $\left(\mu \mathrm{g} \mathrm{m}^{-3} \mathrm{~d}^{-1}\right), \mathrm{V}=$ reactor volume $\left(\mathrm{m}^{3}\right), \mathrm{R}=$ solid retention time (days). $\mathrm{n} / \mathrm{c}=$ not calculated 

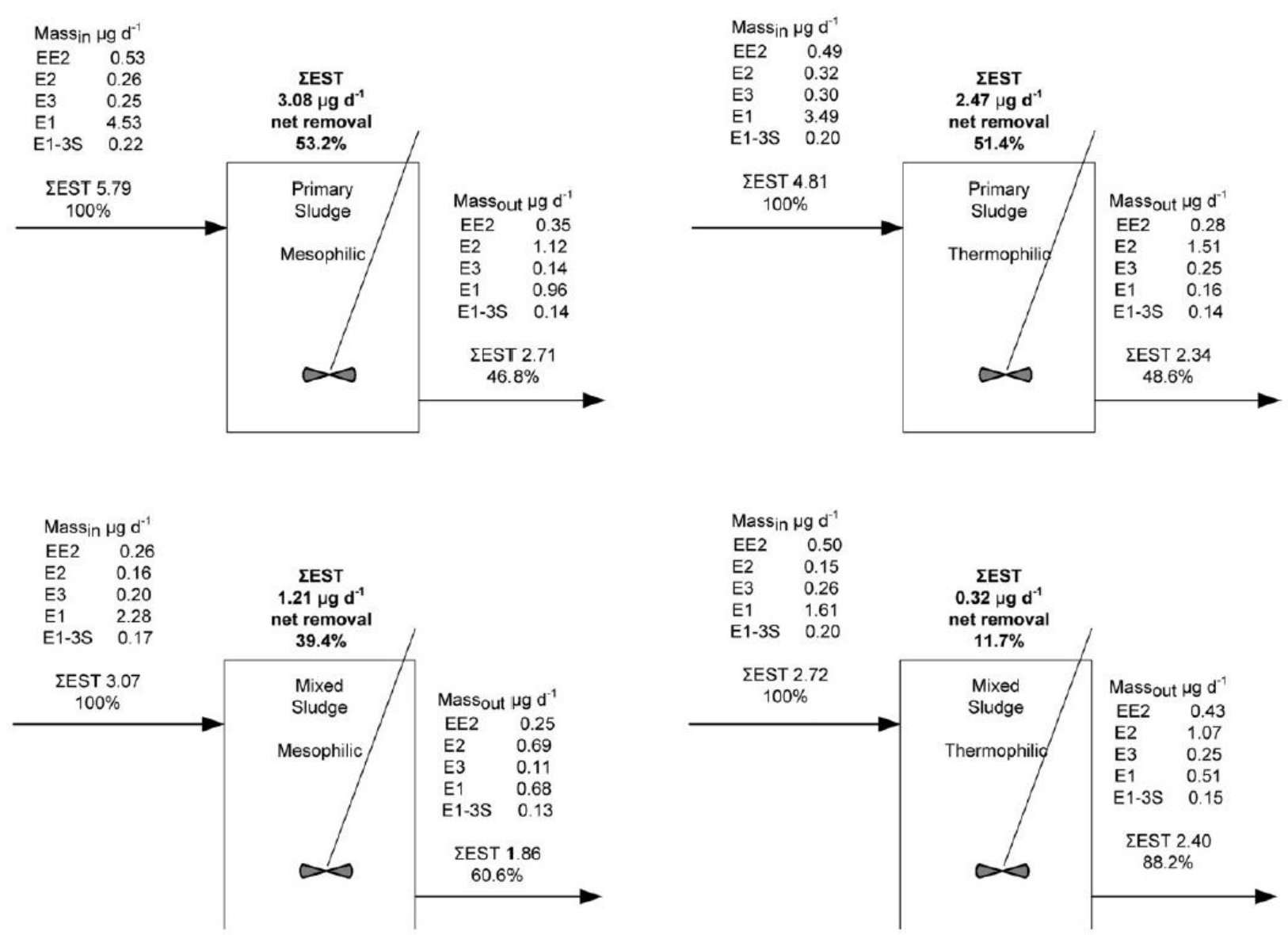

Fig. 2. Mass flux $\left(\mu \mathrm{g} \mathrm{d}^{-1}\right)$ for steroid estrogens at the start and at the end of the anaerobic mesophilic and thermophilic digestion trials for both sludge types.

The behaviour of E1-3S and E3 did not appear to exhibit any differences between the two sludge types. However, EE2 removal appeared higher in the primary sludge reactors with $34 \%$ and $43 \%$ removal in the mesophilic and thermophilic digesters respectively compared to the mixed sludge digesters at $4 \%$ and $14 \%$ for mesophilic and thermophilic temperatures respectively (Table 2). The range of removal efficiencies for EE2 under mesophilic and thermophilic conditions is consistent with the observations of Carballa et al. [14] who reported about $40 \%$ removals under both conditions.

\subsection{Effect of temperature on the removal of steroid estrogens}

Under thermophilic conditions greater formation of E2 occurred for both primary and mixed sludge with the highest formation achieved in mixed sludge (-621\%) compared to $-367 \%$ for primary sludge (Table 2 ). The first order rate constants are also approximately double at $0.05 \mathrm{~d}^{-1}$ under thermophilic conditions compared to $0.026 \mathrm{~d}^{-1}$ under mesophilic conditions 
(Table 2). Therefore, as expected this biochemical reaction was strongly influenced by temperature proceeding faster under thermophilic conditions.

In addition a positive effect of loading was observed on the biotransformation of steroid estrogens. Overall greater percentage removals occurred under thermophilic conditions in comparison to mesophilic conditions (Table 2). However, the mesophilic digesters were more highly loaded than the thermophilic digesters with $\Sigma$ EST loadings differing by 2.4 times in comparison to the thermophilic digesters (Table 1). As a result mesophilic digestion removed 2.5-7.6 times more $\Sigma E S T$ than the thermophilic digestion of primary and mixed sludge respectively over the six retention times. This was mirrored by the rate of $\Sigma E S T$ removal in terms of VS destroyed under mesophilic conditions which was 4.8-14 times higher than the rate of removal observed under thermophilic conditions for primary and mixed sludge respectively. The exception to this was for EE2 where the rate of removal was higher under thermophilic conditions.

This study and that of Carballa et al. [30] both observed biodegradation, which does not concur with the conclusion of de Mes et al. [15], who reported that the most likely removal mechanism of steroid estrogens during anaerobic digestion was adsorption. However, if adsorption was the only removal mechanism this would be expected to potentially decrease with temperature [34]. Carballa et al. [30] observed removal percentages of $(\Sigma E 1+E 2)$ of $85 \pm 10 \%$ during mesophilic and thermophilic sludge digestion.

In this study lower removals were observed with up to half of $\Sigma E 1+E 2$ biodegraded. In primary sludge at mesophilic and thermophilic temperatures 57\% removal was observed and $43 \%$ and $10 \%$ removal was observed for mixed sludge at mesophilic and thermophilic temperatures respectively (Fig. 2). This would be contrary to what would be expected if physico-chemical adsorption alone were responsible for the changes observed. However, further experimental work would be required to fully clarify the possible impact of adsorption capacity. No transformations of E1 and E2 were observed by Czajaka and Londry [32] in sterile sediments. However, transformations of E2 toE1 occurred in samples which had not been sterilized and this was attributed to biological inter-conversion under anaerobic conditions possibly catalysed by other biological conversions. Higher levels ofE1 were observed in the sludge entering an anaerobic digester than leaving in the treated sludge suggesting the conversion of E1 to E2 [35] providing further potential evidence of biotransformation. The de-conjugation of E1-3S, and thus its conversion to E1, appeared to be unaffected by temperature as the percent removal range has a maximum of $7 \%$ between thermophilic and mesophilic temperatures for the equivalent sludge types (Table 2). In the 
study by de Mes [15] with anaerobic treatment of swine manure in an UASB it was concluded that de-conjugation was not occurring to a substantial degree $(70 \%$ of E1 was in a conjugated form) in this study only $10 \%$ of the influent $\mathrm{E} 1$ was conjugated as E1-3S. Nevertheless, although temperature did not appear to have an effect on de-conjugation there would appear to be a small effect on the removal of EE2 with an increase of $11 \%$ between the mesophilic and thermophilic temperatures for both sludge types.

\subsection{Effect of retention time on the removal of steroid estrogens}

Under thermophilic conditions over $80 \%$ of the E1 was transformed within $45 \mathrm{~d}$ (3 SRT) for both primary and mixed sludge. After this period biotransformations of E1 and E2 reached equilibrium(Fig. 1). Similarly, under mesophilic conditions biotransformation changes were again greater over the first three retention periods.

Thus, although the impact of retention time cannot be isolated from the impact of temperature, retention time has a significant effect on the reduction of $E 1$ to $E 2$ with the bulk of the transformation being observed within $45 \mathrm{~d}$ under thermophilic conditions and 90 d for mesophilic conditions.

This reduction of E1 to E2 could be mediated by hydrogen or other organic electron donors as is the case for some aromatic and chlorinated organic compounds [36,37]. The oxidation of E2to E1 under anaerobic conditions is unlikely to provide energy to the cells involved and therefore E2 is used instead as an electron acceptor [32]. However, there appears to be evidence that moreE1 is biodegraded than is reduced to E2 in primary sludge under thermophilic digestion conditions. Detailed examination of Fig. 1indicates that after $60 \mathrm{~d}$ E2 is over $300 \%$ of the mass of $\mathrm{E} 1$. This trend was also observed for the mixed thermophilic sludge. In addition these digesters had the lowest percentage removal of E3 observed(Table 2 ) where only $17 \%$ or $4 \%$ was removed in comparison to $>43 \%$ at mesophilic conditions which implies that E1 had also been converted to E3.3.4. Effect of sludge type on the removal of nonyl phenolethoxylates. The differences in concentration between the two sampling periods (April 2007 and 2008) for the sum of the NPEOs appears consistent with the steroid estrogens with overall higher concentrations (by a factor of 1.8) detected for the 2007 sampling period(mesophilic) compared to the 2008 sampling period (thermophilic) for primary sludge and a factor of 2.7 for the mixed sludge. The most striking difference, however, is in the distribution of the breakdown products of NP3-12EO between 2007 and 2008. In the 2007 primary sludge the breakdown products were overwhelmingly the carboxylated species at $26.5 \mathrm{mg} \mathrm{kg}^{-1} \mathrm{dw}$ compared to $0.06 \mathrm{mg} \mathrm{kg}^{-1} \mathrm{dw}$ in2008. By 
comparison the concentration of NP1-2EO in the primary sludge was $2.1 \mathrm{mg} \mathrm{kg}^{-1} \mathrm{dw}$ in 2007 and $15 \mathrm{mg} \mathrm{kg}^{-1} \mathrm{dw}$ in 2008. This trend was comparable for the mixed sludge with the carboxylated species at $241.5 \mathrm{mg} \mathrm{kg}^{-1} \mathrm{dw}$ in 2007 and $0.1 \mathrm{mg} \mathrm{kg}^{-1} \mathrm{dw}$ in 2008 .

Whilst the concentration of NP1-2EO in 2007 was $1.6 \mathrm{mg} \mathrm{kg}^{-1} \mathrm{dwfor}$ the mixed sludge and $90 \mathrm{mg} \mathrm{kg}^{-1} \mathrm{dw}$ in 2008 implying that the breakdown to the NPECs had not occurred in 2008 possibly due to some operational alterations at the works affecting the solids and/or hydraulic retention times or food to micro-organism ratio in the activated sludge plant which can effect NPEO breakdown[38].

Total NP1-2EO concentrations in the mixed sludge were higher than the primary sludge, this was due to the polar nature of these compounds and their poor removal during primary sedimentation [27]. However, the breakdown products produced during biological treatment are more hydrophobic and are therefore much better removed than the parent compounds leading to higher concentrations in the biomass and hence in the mixed sludge [2,24]. Therefore, mixed sludge NP1-2EO concentrations reflect the breakdown which has occurred during the biological waste water treatment producing the WAS component of the mixed sludge.

The influent concentrations of NP were higher in the primary sludge at $0.5 \mathrm{mg} \mathrm{kg}^{-1} \mathrm{dw}$ in 2007 and $2.2 \mathrm{mg} \mathrm{kg}^{-1} \mathrm{dw}$ in2008 in comparison with the mixed sludge at $0.2 \mathrm{mg} \mathrm{kg}^{-1} \mathrm{dw}$ in 2007 and $0.15 \mathrm{mg} \mathrm{kg}^{-1} \mathrm{dw}$ in 2008 . This was slightly lower than values reported by Minamiyama et al. [39]. Primary sludge had higher concentrations by c. $35 \%$ of the NPEOs compared to the mixed sludge. However, the degradation products e.g. the NPECs were higher in the mixed sludge which was consistent with the biodegradation of the parent compound in the activated sludge process and the incorporation of these breakdown products into the WAS a component of the mixed sludge. The higher loading of the NPECs in the mesophilic mixed sludge were also reflected in higher removals of NPECs $\left(6 \mathrm{mg} \mathrm{d}^{-1}\right)$ over the six retention periods (Fig. 3). Overall, greater removal of $\Sigma$ NPEOs was observed for the mixed sludge $>50 \%$ in comparison to primary sludge. This reflected results of Barret et al. [40] who observed greater metabolism of polycylic aromatic hydrocarbons (PAHs), 7 polychlorobiphenyls (PCBs) and NP in secondary sludge digestion. In addition Patureau et al. [41] also observed the removal of NP1-2EO and NP in a mixed sludge under mesophilic anaerobic conditions. 

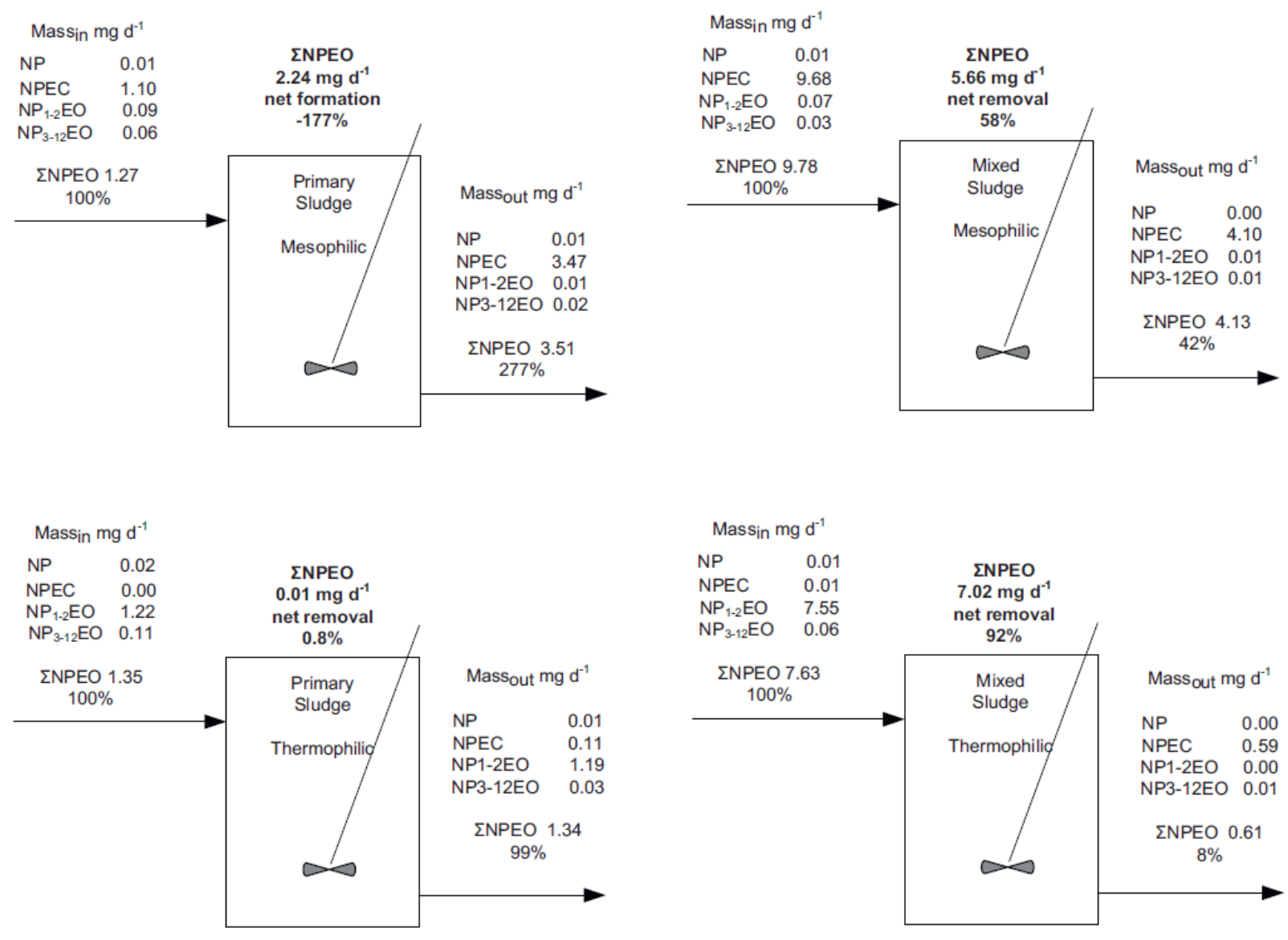

Fig. 3. Mass flux ( $m g ~ d-1)$ for alkylphenol ethoxylates at the start and at the end of the anaerobic mesophilic and thermophilic digestion trials for both primary and mixedsludge types.

\subsection{Effect of temperature on the removal of NPEOS}

The removal efficiency of nonylphenolics ( $\Sigma$ NPEOs) in the mixed sludge was $92 \%$ for thermophilic digestion compared to $58 \%$ for mesophilic digestion. Although primary sludge also exhibited higher removal efficiencies under thermophilic conditions this was less pronounced due to the build up of the carboxylated and NP1-2EO compounds (Table 2). In comparison a reduction in carboxylated concentrations was observed for mixed sludge under thermophilic conditions. A reduction was also observed for the mixed sludge carboxylated compounds under mesophilic conditions even though high starting concentrations (241.5 mg kg${ }^{-1} \mathrm{dw}$ ) were recorded.

The effect of temperature on the biodegradation of the longer chain NP3-12EO in the primary sludge was negligible with equivalent concentrations of $0.4 \mathrm{mg} \mathrm{kg}^{-1} \mathrm{dw}$ remaining in the digester effluent for both mesophilic and thermophilic digesters at the sixth retention period. A moderately faster rate of removal was observed at the thermophilic temperature 
with NP3-12EO concentrations $<0.8 \mathrm{mg} \mathrm{kg}^{-1} \mathrm{dw}$ being observed after one retention time (15 d).

Nonylphenol only accumulated in the mixed sludge thermophilic digesters during the first three retention times. Then from day 60 through to day 90 NP was removed. Overall removal of NP was observed at all temperatures with treated sludge concentrations of 0.2 $\mathrm{mg} \mathrm{kg}^{-1} \mathrm{dw}$ and $0.1 \mathrm{mg} \mathrm{kg}^{-1} \mathrm{dw}$ observed for primary sludge under mesophilic and thermophilic conditions respectively whilst for mixed sludge the final NP concentrations were $0.08 \mathrm{mg} \mathrm{kg}-1 \mathrm{dwand} 0.03 \mathrm{mg} \mathrm{kg}^{-1} \mathrm{dw}$ respectively for mesophilic and thermophilic conditions. The NP1-3ECs initially accumulated in the primary sludge under both mesophilic and thermophilic conditions and no overall removal of NP1-3EC appeared to occur under thermophilic conditions (Fig. 3). However, in the mixed sludge no accumulation of NP1-3ECs was observed at either temperature and overall removal of NP1-3ECs was observed for the mixed sludge mesophilic digestion (Fig. 3). Short-chained nonylphenolics in primary sludge did not accumulate under mesophilic conditions, however some persistence of NP1EO was observed in the thermophilic digesters.

The NP1EO persistence could be partially explained by the higherNP3-12EOs loadings in these digesters, which resulted in metabolic products like NP1-2EOs in anaerobic conditions [42].

\section{Conclusions}

1. Anaerobic digestion affords protection of the re-use environment from contamination by steroid estrogens and NPEOs. The two sludge types studied (primary and mixed sludge) exhibited different behaviour with primary sludge showing superior removal for steroid estrogens and mixed sludge higher removal for NPEOs.

2.In both types of untreated sludges E1 predominated, constituting 69-78\% of the total estrogens. In the mixed sludge, containing WAS capable of biodegrading E1, higher concentrations of E3 were observed which was the ultimate breakdown product ofE1 and E2.

3. Overall removal of $\Sigma E S T$ was $>50 \%$ for primary sludge under both mesophilic and thermophilic conditions whilst for mixed sludge overall removals were lower at $39 \%$ and $12 \%$ respectively reflecting bulk organic solids removal during digestion.

4. In the mixed sludge NP1-2EO's were higher than in the primary sludge, reflecting the breakdown which had occurred during secondary aerobic (activated sludge) treatment. 
Overall removals were higher in the digestion of mixed sludge in comparison to primary sludge digestion and in comparisons to steroid estrogen removals were not influenced by the efficiency of solid removal in anaerobic digestion.

5. There is evidence to suggest that the introduction of WAS already aerobically acclimated to estrogens was able to function in the anaerobic environment and enhanced the conversion of E1 to E2.

\section{Acknowledgements}

The authors gratefully acknowledge the financial support from Thames Water and Yorkshire Water. N. Paterakis would also like to thank the Engineering and Physical Sciences Research Council (EPSRC) for the provision of a CASE studentship.

\section{References}

[1] N.D. Bedding, A.E. McIntyre, R. Perry, J.N. Lester, Organic contaminants in the aquatic environment. I. Sources and occurrence, Sci. Total Environ. 25 (1982) 143-167.

[2] T.Y. Chiu, N. Paterakis, M.D. Scrimshaw, E. Cartmell, J.N. Lester, A critical review of the formation of mono-and dicarboxylated metabolic intermediates of alkylphenol polyethoxylates during wastewater treatment and their environmental significance, Crit. Rev. Environ. Sci. Technol. 40 (2010) 199-238.

[3] Y.K.K. Koh, T.Y. Chiu, A. Boobis, E. Cartmell, M.D. Scrimshaw, J.N. Lester, Treatment and removal strategies of natural estrogens in the wastewater, Environ. Technol. 29 (2008) 245-268.

[4] O.A.H. Jones, N. Voulvoulis, J.N. Lester, The fate of human pharmaceuticals in wastewater treatment processes, Crit. Rev. Environ. Sci. Technol. 35 (2005) 401-427.

[5] O.A.H. Jones, N. Voulvoulis, J.N. Lester, The occurrence and removal of selected pharmaceutical compounds in an English sewage treatment works utilizing activated sludge treatment, Environ. Pollut. 145 (2007) 738-744.

[6] H. Andersen, H. Siegrist, B. Halling-Sørensen, T.A. Ternes, Fate of estrogens in a municipal sewage treatment plant, Environ. Sci. Technol. 37 (2003) 4021-4026.

[7] K.M. Lai, M.D. Scrimshaw, J.N. Lester, Biotransformation and bioconcentration of steroid estrogens by Chlorella vulgaris, Appl. Environ. Microbiol. 68 (2002) 859-864.

[8] K.M. Lai, M.D. Scrimshaw, J.N. Lester, Prediction of the bioaccumulation factors and body burden of natural and synthetic estrogens in aquatic organisms in river systems, Sci. Total Environ. 289 (2002) 159-168.

[10] O.A.H. Jones, P. Green, N. Voulvoulis, J.N. Lester, Questioning the excessive use of advanced treatment to remove organic micropollutants from wastewater, Environ. Sci. Technol. 41 (2007) 5085-5089.

[11] N. Voulvoulis, J.N. Lester, Fate of organotins in sewage sludge during anaerobic digestion, Sci. Total Environ. 371 (2006) 373-382. 
[12] R.S.K. Buisson, P.W.W. Kirk, J.N. Lester, Determination of chlorinated phenols in water, wastewater and wastewater sludge, Chromatogr. Sci. 22 (1984) 339-342.

[13] A.M. Robertson, J.N. Lester, Supercritical fluid extraction of s-triazines and phenylurea herbicides from sediment, Environ. Sci. Technol. 28 (1994) 346-351.

[14] M. Carballa, F. Omil, T. Ternes, J.M. Lema, Fate of pharmaceutical and personal care products (PPCPs) during anaerobic digestion of sewage sludge, Water Res. 41 (2007) 2139-2150.

[15] T.Z.D. de Mes, K. Kujawa-Roeleveld, G. Zeeman, G. Lettinga, Anaerobic biodegradation of estrogens_hard to digest, Water Sci. Technol. 57 (2008) 1177-1182.

[16] R.L. Gomes, M.D. Scrimshaw, J.N. Lester, Fate of conjugated natural and synthetic steroid estrogens in crude sewage and activated sludge batch studies, Environ. Sci. Technol. 43 (2009) 3612-3618.

[17] J. Montgomery-Brown, M. Reinhard, Occurrence and behavior of alkylphenol polyethoxylates in the environment, Environ. Eng. Sci. 20 (2003) 471-486.

[18] G. Hernandez-Raquet, A. Soef, N. Delgenes, P. Balaguer, Removal of the endocrine disruptors nonylphenol and its estrogenic activity in sludge treatment processes, Water Res. 41 (2007) 2643-2651.

[19] A. Soares, B. Guieysse, B. Jefferson, E. Cartmell, J.N. Lester, Nonylphenol in the environment: a critical review on occurrence, fate, toxicity and treatment in wastewaters, Environ. Int. 34 (2008) 1033-1049.

[20]B.V. Chang, F. Chiang, S.Y. Yuan, Anaerobic degradation of nonylphenol in sludge, Chemosphere 59 (2005) 1415-1420.

[21] P.F.X. Corvini, A. Schaffer, D. Schlosser, Microbial degradation of nonylphenol and other alkylphenols: our evolving view, Appl. Microbiol. Biotechnol. 72 (2006) 223-243.

[22] T. Eggen, A. Majcherczyk, Removal of polycyclic aromatic hydrocarbons (PAH) in contaminated soil by white rot fungus Pleurotus ostreatus, Int. Biodeterior. Biodegrad. 41 (1998) 111-117.

[23] $M \stackrel{\circ}{ }$ C. Dictor, N. Berne, O. Mathieu, A. Moussay, A. Saada, Influence of ageing of polluted soils on bioavailability of phenanthrene, Oil Gas Sci. Technol. 58 (2003) 481-488. [24] K. Koh, T.Y. Chiu, A.R. Boobis, E. Cartmell, M.D. Scrimshaw, J.N. Lester, A sensitive and robust method for the determination of alkylphenol polyethoxylates and their carboxylic acids and their transformation in a trickling filter wastewater treatment plant, Chemosphere 73 (2008) 551-556.

[25] R.L. Gomes, E. Avcioglu, M.D. Scrimshaw, J.N. Lester, Steroid-estrogen determination in sediment and sewage sludge: a critique of sample preparation and chromatographic/mass spectrometry considerations, incorporating a case study in method development, Trends Anal. Chem. 23 (2004) 737-744.

[26] T.Y. Chiu, Y.K.K. Koh, N. Paterakis, A.R. Boobis, E. Cartmell, K.H. Richards, J.N. Lester, M.D. Scrimshaw, The significance of sample mass in the analysis of steroid estrogens in sewage sludges and the derivation of partition coefficients in wastewaters, J. Chromatogr. A 1216 (2009) 4923-4926.

[27] Y.K.K. Koh, T.Y. Chiu, N. Paterakis, A. Boobis, M.D. Scrimshaw, J.N. Lester, E. Cartmell, Fate and occurrence of alkylphenolic compounds in sewage sludges determined by liquid chromatography tandem mass spectrometry, Environ. Technol. 30 (2009) 14151424. 
[28] Metcalf and Eddy Inc., Wastewater Engineering, Treatment, Disposal and Reuse, 4th edition, McGraw-Hill, New York, USA, 2003.

[29] M. Muller, S. Combalbert, N. Delgenès, V. Bergheaud, V. Rocher, P. Benoît, P.JP. Delgenès, D. Patureau, G. Hernandez-Raquet, Occurrence of estrogens in sewage sludge and their fate during plant-scale anaerobic digestion, Chemosphere 81 (2010) 65-71.

[30] M. Carballa, F. Omil, A ${ }^{\circ}$ C. Alder, J.M. Lema, Comparison between the conventional anaerobic digestion of sewage sludge and its combination with a chemical or thermal pretreatment concerning the removal of pharmaceuticals and personal care products, Water Sci. Technol. 53 (2006) 109-117.

[31] A. Hospido, M. Carballa, M. Moreira, F. Omil, J.M. Lema, G. Feijoo, Environmental assessment of anaerobically digested sludge reuse in agriculture: potential impacts of emerging micropollutants, Water Res. 44 (2010) 3225-3233.

[32] P. Czajka, K. Londry, Anaerobic biotransformation of estrogens, Sci. Total Environ. 367 (2006) 932-941.

[33] T. Stephenson, R. Perry, J.N. Lester, The behaviour of nitrilotriacetic acid during the anaerobic digestion of cosettled sewage sludge, Water Res. 17 (1983) 1337-1341.

[34] S.L. Ji, Y.Y. Yang, Z.P. Qin, J.T. Li, T. Sun, Isothermal adsorption of steroid estrogens onto aerobic granular sludge, J. Beijing Univ. Technol. 35 (2009) 1537-2154.

[35] S. Matsui, H. Takigami, T. Matsuda, N. Taniguchi, J. Adachi, H. Kawami, Y. Shimizu, Estrogen and estrogen mimics contamination in water and the role of sewage treatment, Water Sci. Technol. (2000) 173-179.

[36] J. Gerritse, O. Drzyzga, G. Kloetstra, M. Keijmel, L.P. Wiersum, R. Hutson, M.D. Collins, $\mathrm{J}{ }^{\circ} \mathrm{C}$. Gottschal, Influence of different electron donors and acceptors on dehalorespiration of tetrachloroethene by Desulfitobacterium frappieri TCE1, Appl. Environ. Microbiol. 65 (1999) 5212-5221.

[37] D.R. Lovley, D.J. Lonergan, Anaerobic oxidation of toluene, phenol, and p-cresol by the dissimilatory iron-reducing organism, GS-15, Appl. Environ. Microbiol. 56 (1990) 18581864.

[38] E. McAdam, J.P. Bagnall, A. Soares, Y.K.K. Koh, T.Y. Chiu, M.D. Scrimshaw, J.N. Lester, E. Cartmell, Fate of alkylphenolic compounds during activated sludge treatment: impact of loading and organic composition, Environ. Sci. Technol. 45 (2011) 248-254.

[39] M. Minamiyama, S. Ochi, Y. Suzuki, Fate of nonylphenol polyethoxylates and nonylphenoxy acetic acids in an anaerobic digestion process for sewage sludge treatment, Water Sci. Technol. 53 (2006) 221-226.

[40] M. Barret, G. Cea Barcia, A. Guillon, H. Carrere, D. Patureau, Influence of feed characteristics on the removal of micropollutants during the anaerobic digestion of contaminated sludge, J. Hazard. Mater. 181 (2010) 241-247.

[41] D. Patureau, N. Delgenes, J.P. Delgenes, Impact of sewage sludge treatment processes on the removal of the endocrine disrupters nonylphenol ethoxylates, Chemosphere 72 (2008) 586-591.

[42] P.H. Brunner, S. Capri, A. Marcomini, W. Giger, Occurrence and behaviour of linear alkylbenzene sulphonates, nonylphenol, nonylphenol mono- and nonylphenol diethoxylates in sewage and sewage sludge treatment, Water Res. 22 (1988) 1465-1472. 